\title{
PRIMENA TEORIJE SELF-DETERMINACIJE U ISTRAŽIVANJIMA RADNE MOTIVACIJE
}

\author{
Nebojša Majstorović ${ }^{1}$ \\ Odsek za psihologiju \\ Filozofski fakultet u Novom Sadu
}

Teorija self-determinacije razvija integrativan pristup delikatnom naučnom problemu motivacije tako što povezuje inherentne potrebe rasta sa aktivnom prirodom čoveka koja, pri svojoj normalnosti $i$ u naklonjenim uslovima sredine, teži da razvije autonoman stil regulacije ponašanja kao i da integriše životno iskustvo i ličnosne dispozicije u koherentan sistem selfa. Teorija razmatra i slučaj preteranog spoljnjeg pritiska koji dovodi do frustracije osnovnih potreba rasta kao i do razvoja kontrolisane motivacije ili stanja amotivacije. Pretpostavke ove teorije su testirane u brojnim domenima kao što su učenje, rad, sport, intimni odnosi, pro-socijalno ponašanje $i$ mnogim drugim. Cilj ovog teksta je da prikaže dosadašnja iskustva u primeni teorije self-determinacije $u$ analizi organizacijskog ponašanja, da pozicionira ovu teoriju u odnosu na druge teorije radne motivacije, kao i da ukaže na moguće pravce budućih istraživanja koja bi proizilazila iz njenog konceptualnog okvira.

Ključne reči: self-determinacija, motivacija za rad, self, regulacija ponašanja

\footnotetext{
${ }^{1}$ E-mail:majstorovicn@unsff.ns.ac.yu
} 
'SDT allows us to not only better understand human processes in a number
of areas (education, work, leisure activities, parenting, etc.) but also to
guide applications and interventions to ameliorate the human condition.'

[SDT nam omogućava ne samo da bolje razumemo psihološke procese u brojnim oblastima (obrazovanje, rad, dokolica, roditeljstvo, itd.) nego i da usmeravamo programe i intervencije za poboljšanje okolnosti u kojima ljudi žive.]

(Vallerand, Pelletier \& Koestner, 2008, str. 260)

Osnovni cilj ovog teksta je da se srpskoj psihološkoj nauci približi njoj uglavnom nepoznata i veoma perspektivna teorija self-determinacije (SDT; Deci \& Ryan, 1985, 2002). SDT donosi relativno novi pristup kontroverznoj temi motivacije i uopšte regulacije motivisanog ponašanja individue. Ovaj cilj će biti ostvaren kroz prikaz osnovnih pretpostavki ove teorije kao i skupa meta-teorija koje opisuju značaj bazičnih psihičkih potreba, kauzalnih orijentacija osobe, podrške sredine i self-determinacije u regulaciji ponašanja. Na početku, opisaćemo okolnosti u kojima se odigrala eksperimentalna kontroverza iz koje je i začeta ideja o self-determinaciji kao motivacionom kontinuumu.

Poznato da su procesne teorije motivacije (npr. Vroom, 1984) uvele konstrukte poput očekivanja i valence kako bi, kroz individualnu procenu radnih potencijala i vrednosti nagrade, bile u stanju da objasne proces motivisanja zaposlenog. Jednako tako, poznato je i da su Porter i Lawler (1968) uveli pojmove intrinzičke i ekstrinzičke motivacije kako bi obuhvatili potencijalno sve faktore zadovoljstva poslom. Tu se misli na faktore koji slede iz samog obavljanja posla (njegov sadržaj i aktivnosti koje on zahteva) i one koji se tiču efekata koji slede iz te radne aktivnosti (novac, status, moć, popularnost). Isti autori su naglašavali potrebu za redizajniranjem posla kako bi se maksimiziralo radno zadovoljstvo. Predlagali su usložnjavanje radne uloge, povećanja nagrada kao i strukturno povezivanje učinka sa visinom kompenzacije. Ovakav pristup se zasnivao na hipotezi o aditivnosti intrinzičke i ekstrinzičke motivacije, odnosno verovanju da će subsumiranje unutrašnjih i spoljašnjih motivatora dovesti do maksimalno mogućeg zadovoljstva poslom i, time, motivacije za rad. Testirajući ovu hipotezu Deci (1971) je došao do otkrića da aditivnost ne važi, odnosno, da intrinzička i ekstrinzička motivacija stoje u znatno složenijem odnosu. Naime, eksperimentalno je utvrdio da materijalne nagrade ne dodaju motivaciju na već postojeću intrinzičku motivaciju nego je upravo umanjuju. Naime, on je od ispitanika tražio da reprodukuju određene oblike sa slagalicama (engl. Puzzle) za određeno vreme i ako to urade dobiju 1 dolar (E grupa) ili da takva nagrada nije ponuđena (K grupa). Analiza razlika u trajanju perioda bavljenja slagalicama u tzv-im 'pauzama eksperimenta' otkrilo je da, inicijalno jednako intrinzički zainteresovani ispitanici za 
igranje sa slagalicama, su pokazali značajno duže vreme tog perioda ukoliko nisu bili nagrađivani za uspeh u reprodukciji zadate konfiguracije ( $\mathrm{K}$ grupa). Nalaz iz ovog i drugih eksperimenata govorili su da uvođenje spoljašnjih standarda umanjuje intrinzički interes ukoliko je on prethodno postojao. Isti autor nalazi i da verbalne nagrade za postignuće proizvode upravo oprečan efekat, unapređujući već postojeću intrinzičku motivaciju. Ovo otkriće je pokrenulo niz eksperimenta kako bi se identifikovao psihološki mehanizam iza eksperimentalnog efekta materijalne nagrade. Deci (1975) i Deci \& Ryan (1980) su na osnovu dodatnih istraživanja predložili teoriju kognitivne evaluacije kojom se gornji efekat uvođenja nagrade objašnjava umanjenim osećanjem autonomnosti $u$ obavljanju aktivnosti za koju je osoba već bila intrinzički zainteresovana, kao i time da uvođenje materijalne nagrade izaziva premeštanje lokusa uzročnosti od unutrašnjeg ka spoljašnjem (tj. više ne radim nešto zato što to inače volim nego zato što sam plaćen za to). Nadalje, oni su pronašli i to da uvođenje kazne umanjuje osećaj kompetentnosti što za posledicu ima pojavu amotivisanosti kod osobe, odnosno, gubitak i intrinzičke i ekstrinzičke motivacije za datu aktivnost (Deci \& Ryan, 1985a).

Eksperimentalni nalazi poput ovih su svakako vredni za razumevanje motivisanog ponašanja uopšte, a posebno mogu biti korisni u analizi motivisanog radnog ponašanja. Ipak, primena ovih nalaza na modeliranje organizacijskog ponašanja se sudarila sa uobičajenom praksom da se radnici upravo najčešće nagrađuju prema učinku kao i sa praktičnim teškoćama koje prate vertikalno obogaćivanje radne uloge. Znači li to da su plate iskorenile intrinzičku motivaciju u organizacijama, ili da li je usložnjavanje uloge jedini način da se unapredi intrinzička motivacija za rad? Da bi se proverila konačna upotrebna vrednost ovih saznanja Deci \& Ryan (1985b) preduzimaju nova istraživanja u oblasti internalizacije spoljašnjih regulativa i pratećih vrednosti, kao i nova testiranja individualnih razlika u domenu kauzalnih orijentacija. To je dovelo do formulisanja teorije self-determinacije (SDT) u kojoj se pojavljuje kontinuumu self-determinacije sa amotivacijom i intrinzičkom motivacijom na njegovim krajevima i ekstrinzičkom motivacijom sa svoja četiri oblika između njih (Slika 1).

Osnovni cilj stavljen pred SDT je da objasni razliku između amotivacije i motivacije, autonomne i kontrolisane motivacije kao i da ukaže na značaj sredinskih uslova i individualnih faktora (bazičnih psiholoških potreba i kauzalnih orijentacija) na formiranje autonomne ili kontrolisane regulacije ponašanja. Autonomna regulacija uključuje intrinzičku motivaciju, zadovoljene bazične psihološke potrebe (kompetencija, odnosi sa drugima i autonomija) kao i podržavajuću, otvorenu i blagonaklonu sredinu. Kontrolišuća regulacija se zasniva na presudnom uticaju spoljašnjih faktora u bihevioralnoj regulaciji ili, pak, na introjekciji tak- 
vih uticaja, kao i na sredinskim faktorima koji ne dopuštaju razvoj sigurnih odnosa sa drugim važnim osobama, niti sticanje osećanja autonomije i kompetentnosti u radu. Povećan stepen autonomnosti govori o značajnijem uticaju ličnih interesovanja i autentičnih izbora u regulaciji ponašanja. Ne primer, značajno su različiti efekti na regulaciju ponašanja kod radnika kada rukovodilac jednostavno zahteva određenu promenu u ponašanju ili kada pruži mogućnost podređenom da internalizuje taj zahtev, integriše ga i doživi kao važan za tim ili za njega samog. Jasno je da će kvalitet radne motivacije u ova dva slučaja biti različit. Da li to ima značaja za radno ponašanje i učinak?

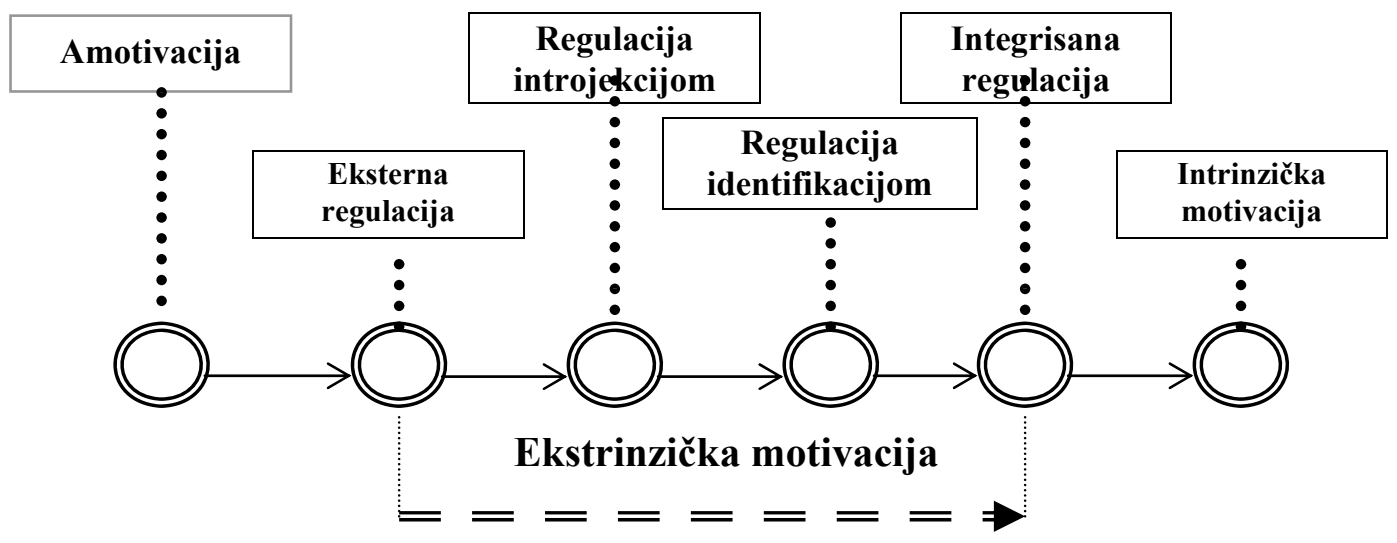

\section{Self-determinacija}

Slika 1. SDT model motivacije

Istraživanja su već pokazala da autonomna regulacija radnog ponašanja korelira sa afektivnom predanošću organizaciji kao i sa većom spremnošću za prihvatanje organizacijskih ciljeva (Gagne \& Koestner, 2002). Neke prethodne studije takođe nalaze negativnu korelaciju između percepcije ekstrinzičkih nagrada i snage intrinzičke motivacije za rad (Eden, 1975), kao i da uvođenje plaćanja po učinku u neprofitnim organizacijama umanjuje intrinzičku motivaciju kod njihovog osoblja (Deckop \& Cirka, 2000). Nadalje, Deci et al. (1989) nalaze da je autonomna podrška rukovodilaca (podrška autonomnoj regulaciji kod podređenih u obliku imanja razumevanja za njihov stav ili problem, davanja mogućnosti izbora, pružanja informacija o radnoj efikasnosti i podrška inicijativi na poslu) pozitivno povezana sa zadovoljstvom poslom, većim poverenjem u menadžment kompanije i sa pozitivnijim stavom prema radnim obavezama. Sem toga, poka- 
zalo se da podrška autonomiji u radu vodi ka zadovoljenju potreba za kompetentnošću, odnosima i autonomiji ali, isto tako, i većem radnom učinku, lakšem prihvatanju organizacijskih promena i boljoj prilagođenosti zaposlenih (npr. Baard et al., 2004; Deci et al., 2001). Autonomna motivacija se nalazi u osnovi veće uključenosti osobe u posao (engl. job involvement) kao i višeg kvaliteta rada, pre svega u smislu većeg zalaganja i lakšeg ostvarivanja radnih ciljeva (Beaugh, 1985; Sheldon \& Elliot, 1998). U 13 meseci dugoj longitudinalnoj studiji ispitivan je kauzalni odnos između autonomne motivacije i organizacijske predanosti (Gagne \& Koestner, 2002; Gagne et al., 2004). Utvrđeno je da inicijalna autonomna radna motivacija uzrokuje pojavu organizacijske predanosti ali da inicijalna predanost, sama po sebi, ne dovodi do kasnije autonomne motivacije. Bono \& Judge (2003) nalaze da podređeni koji rade pod transformacijskim vođom (Burns, 1978) pokazuju i veće zadovoljstvo poslom i veću afektivnu vezanost za organizaciju. Shamir et al. (1998) su takođe utvrdili da transformacijski lideri motivišu time što omogućuju podređenima da se identifikuju sa radnom grupom, da povećaju osećanje samo-efikasnosti kao i da povežu svoje lične vrednosti sa vrednostima radne grupe.

Sve u svemu, ova istraživanja jasno stavljaju u prvi plan pozitivne efekte autonomne motivacije na ukupno organizacijsko ponašanje. Objašnjenje koje nudi SDT je da podrška autonomiji od strane menadžera izaziva pozitivne posledice, jer takva podrška dovodi do zadovoljenja bazičnih psiholoških potreba individua, al i do održanja intrinzičke motivacije za rad, kao i do pune internalizacije i integracije ekstrinzičkih regulativa organizacijskog ponašanja.

\section{Odnos između autonomne motivacije i radnog učinka - detaljnije}

Iako su već navedeni istraživački rezultati koji govore da autonomna radna motivacija najčešće vodi ka boljem učinku, ova relacija svakako zaslužuje više pažnje budući da je to uvek centralna tema u razmatranjima usklađivanja potencijala zaposlenog i poslovnih ciljeva organizacije. Opravdano je postaviti pitanje da li gornji odnos postoji u svim slučajevima ili postoje moderatori i medijatori koji ga menjaju? Grolnick \& Ryan (1987) nalaze uticaj autonomne motivacije na učinak kod manje strukturisanih poslova u kojima se od izvršioca zahteva više fleksibilnosti, kreativnosti i razumevanja radnog procesa. Kod jednostavnijih i monotonih poslova autori ili ne nalaze značajne razlike $\mathrm{u}$ efektu autonomne i kontrolisane motivacije, ili nalaze da kontrolišuća motivacija bolje prognozira učinak. Ispitujući stabilnost efekta kontrolisane motivacije, isti autori otkrivaju da je on kratkoročan te da ekstrinzički regulativi gube svoj uticaj na učinak već sedam dana nakon njihovog uvođenja. Autonomna motivacija ima trajnije efekte na učinak ali i na druge aspekte radnog ponašanja koji su presudni u ostvarenju 
ciljeva poslovanja. Na primer, Matteson \& Ivancevic (1987) su utvrdili da autonomna motivacija ima značajan efekat na radnikovo zadovoljstvo poslom, ukupno psihičko blagostanje, apsentizam i fluktuaciju čak i kod monotonih poslova. Gagne \& Deci (2005) daju model autonomne motivacije za rad sumirajući sve pretpostavke o potencijalnim uzrocima i posledicama autonomne/kontrolisane motivacije za rad (Slika 2). Polazeći od ovog modela Lam \& Gurland (2008) testiraju medijacionu ulogu autonomne/kontrolisane motivacije u odnosu između generalne kauzalne uzročnosti, s jedne, i zadovoljstva poslom i organizacijske predanosti, s druge strane. Rezultati su potvrdili očekivanje da autonomna motivacija deluje kao medijator odnosno da autonomna kauzalna orijentacija osobe utiče delom na formiranje autonomne radne motivacije, da bi potom takva motivacija proizvodila povećan stepen zadovoljstva poslom i predanost organizaciji. Medijacioni efekat kontrolisane radne motivacije nije nađen u ovoj analizi, odnosno zaključeno je da kontrolišuća motivacija ne proizvodi subjektivni kontekst za pojavu zadovoljstva i predanosti u radu. I to je posebno važno otkriće jer vrlo verovatno ukazuje na to da zadovoljstvo poslom ili predanost firmi nisu motivirajući kada je kontrolišuća motivacija dominantna. Na primer, visoko zadovoljstvo platom ili utilitarna predanost (uz odsustvo afektivne i normativne predanosti) ne mora da znači i spremnost na učenje, prihvatanje promena u organizaciji, ili nisku potencijalnu fluktuaciju među zaposlenima.

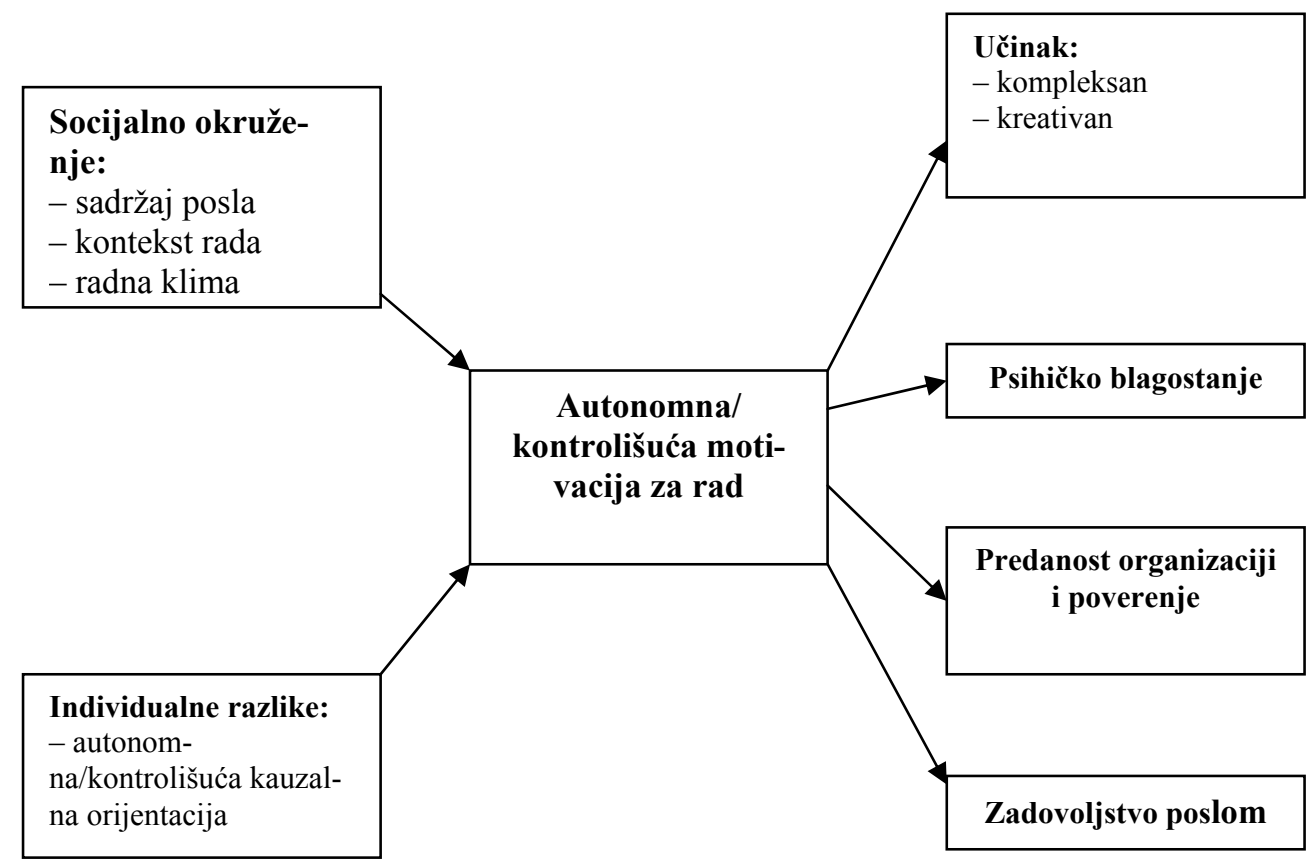

Slika 2. Model motivacije za rad prema SDT 


\section{SDT i druge teorije motivacije za rad}

Da bi se SDT odredila prema drugim teorijama motivacije za rad, i time istakao njen specifičan doprinos u domenu radne motivacije, na ovom mestu biće ukratko razmotrene osnovne sličnosti i razlike među njima.

Odnos između SDT i procesnih teorija motivacije (Vroom, 1984; Porter \& Lawler, 1968) je delom prodiskutovan u kontekstu njihove aditivne hipoteze zadovoljstva poslom. Još je vredno dodati i to da procesne teorije ističu kogniciju kao osnovu za (samo)motivisanje i pojavu spremnosti na zalaganje. Naime, osoba donosi niz odluka o tome da li delovati na određen (npr. pojačan) način i to na bazi sopstvenih očekivanja, odnosno, procena verovatnoća u vezi sopstvenih resursa da izvrši akciju, da će takva akcija dovesti do ishoda, kao i odluku o poželjnosti takvog ishoda. Proizvod takvih subjektivnih procena će delovati motivirajuće ili demotivirajuće da se izvrši radni zadatak na tražen način, da sledi zadatu radnu proceduru, da kupi određen proizvod, da se upiše na određene studije i sl. SDT ne polazi od instrumentalne vrednosti nagrade i procena verovatnoće da se ona postigne, nego zastupa stanovište da spoljašnji uticaji (npr. nova metoda rada, nova radna procedura, posedovanje određenog proizvoda, ili sticanje određenog zanimanja) imaju motivirajuće dejstvo samo ukoliko su u skladu sa bazičnim psihološkim potrebama pojedinca. Pri tom, teorija ističe da postoje individualne razlike $\mathrm{u}$ percepciji i interpretaciji takvih uticaja kao $\mathrm{i}$ da te razlike proizilaze iz prevalentnog stila regulacije ponašanja, odnosno, prethodnog razvojnog iskustva. SDT priznaje da materijalne nagrade mogu imati ličnu vrednost, ali i ističe da takve nagrade razvijaju jedino kontrolišuću motivaciju za rad za koju se ne može reći da je stabilna, jaka, niti blagotvorna za pojedinca i organizaciju.

Teorija postavljanja ciljeva (Goal-setting theory; Locke \& Latham, 1990) i SDT imaju tačku zbližavanja na mestu gde obe ističu važnost sadržaja radnih ciljeva, stepen izazova koji ti ciljevi sadrže, jasnost puta za njihovo ostvarenje kao i značaj smislenog objašnjenja važnosti cilja. Teorija postavljanja ciljeva pretpostavlja da je individualna predstava cilja ključna za njeno maksimalno angažovanje i otuda je važno kako osoba percipira cilj i kako je taj cilj predstavljen. Cilj motiviše ako je jasan, ako je teži ali i ako je poželjan i ostvariv. Ova teorija, za razli$\mathrm{ku}$ od SDT, ne razmatra način regulacije radnog ponašanja kao bitan faktor $\mathrm{u}$ ostvarenju cilja. SDT ističe razliku u kvalitetu radne motivacije koja se javlja kada izvršilac angažuje autonomnu, odnosno, kada sledi kontrolisanu selfregulaciju. Nadalje, SDT ističe i da vrsta self-regulacije ima posledice i na kvalitet učinka, dajući prednost autonomnoj regulaciji i to, pre svega, kod manje strukturisanih poslova. Drugim rečima, nije svejedno ako radnici razumeju važnost 
cilja, prihvataju stepen izazova i znaju kako do njega stići i pri tom očekuju da za trud budu dobro novčano nagrađeni, i ako isti radnici vide svoj pojačan angažman kao doprinos radnom timu, celoj organizaciji, kao realizaciju ličnih vrednosti, ili zato što ih jednostavno čini zadovoljnim kadgod se bave svojim poslom. U prvom slučaju bi teškoća u ispunjenju radnikovih novčanih očekivanja onemogućila ponovno pokretanje radnih resursa, dok u drugom to ne bi bio problem jer su ti ciljevi internalizovani i integrisani u sistem vrednosti i time postali lično važni za izvršioca. Sem toga, postoji i efekat na kvalitet učinka. Na primer, ako jedan viši menadžer reguliše svoje radno ponašanje na kontrolisani način ( $\mathrm{tj}$. često su mu potrebne smernice, saveti, formalni regulativi da bi doneo odluke) to će umanjiti kvalitet njegovog doprinosa u poslu u kome se od njega očekuje da bude upravo kreativan i najčešće autonoman. Nasuprot teorije postavljanja ciljeva, SDT sugeriše da i ako znamo za nekog menadžera da može biti uspešno motivisan ciljevima da to i ne znači da će taj isti menadžer biti uspešan u njihovoj realizaciji ako na putu do njih mora da donese brojne autonomne odluke (na primer, kada se od njega/nje traži da formuliše taktiku poslovanja za svoje odeljenje).

Poput hijerarhijskih teorija potreba (Maslow, 1954; Herzberg, 1966; Alderfer, 1972), SDT isto tako postulira postojanje bazičnih potreba od čijeg zadovoljenja zavisi funkcionisanje i blagostanje pojedinca. Međutim, za razliku od ovih teorija, SDT govori i o načinima njihovog zadovoljenja, ne samo o zadovoljačima koji su prisutni ili odsutni u okruženju. SDT insistira na aktivnoj ulozi pojedinca koji traga za uslovima gratifikacije potreba, odnosno, za uslovima koji će odgovarati aktuelnom obliku regulacije selfa. Hodgins \& Knee (2002) polaze od dominacije nekog od stilova regulacije i opisuju tri tipa selfa (integrisani, egoinvestirajući i impersonalni self). Majstorović (2007, 2008) nalazi da samo jedan od njih (integrisani self) razvija autentičan vrednosni sistem i aktivno koristi taj sistem u zadovoljenju svojih bazičnih psiholoških potreba. Preostala dva tipa selfa (ego-investirajući i impersonalni) ili imaju svoje autentične vrednosti zamenjene drugim 'oficijelnim vrednostima' ili ceo sistem pati od nekonzistentnosti i hronične nerazvijenosti. Time se objašnjava kako se neke osobe odriču svog autentičnog razvoja i okreću gradnji artificijelnog 'ja', u kome vrednosti prestaju da koreliraju sa njihovim sopstvenim potrebama. Dodatna istraživanja otkrivaju i to da je kod tipičnih slučajeva ego-investirajućeg selfa vrednosni sistem 'uspavan', odnosno, da ovakve osobe znatno manje angažuju svoje vrednosti i da se, verovatno, konstantno prilagođavaju spoljašnjim okolnostima kako bi ostvarili ono što i drugi u okruženju takođe žele (Majstorović, 2008). Konačno, razlika između klasičnih teorija potreba i SDT-a je i u tome da je teorija selfdeterminacije tokom poslednjih 30 godina uknjižila značajan broj empirijskih potvrda što nije slučaj i sa teorijama Maslow-a, Herzberg-a i Alderfer-a. 


\section{Koncept autonomne ekstrinzičke motivacije(AEM)}

SDT je jedina teorija koja se koristi konstruktima intrinzičke i ekstrinzičke motivacije i koja opisuje proces transformacije jedne u drugu. Jedan tip motivacije koji se javlja na prelazu između sfera ekstrinzičke i intrinzičke motivacije na kontinuumu self-determinacije je autonomna ekstrinzička motivacija (AEM; Gagne \& Deci, 2005). Autonomna ekstrinzička motivacija se odnosi na spremnost osobe da obavlja zadatke koje smatra važnim za sopstvene ciljeve i vrednosti. Vrlo je važno imati na umu da se radi se o zadacima koje osoba nije sama postavila, već su oni postavljeni spolja. Međutim, ako je cilj koji se želi ostvariti radnim zadatkom integrisan u sistem ličnih ciljeva i vrednosti izvršioca, prateće radno ponašanje postaće regulisano ličnim vrednostima i ciljevima, postaće važnim za osobu i postaće izvorom intrinzičkog zadovoljstva za nju. Pre nekoliko godina istraživači su eksperimentalno i na indirektan način testirali ovakvu hipotezu. Tako Koestner \& Losier (2002) ispituju efekte različitih tipova motivacije na učinak u neinteresantnim radnim zadacima, a koji se smatraju veoma važnim za grupu i koji zahtevaju disciplinovanost i značajno angažovanje. Autori porede tipove motivacije prema radnoj efikasnost i nalaze da su kod ovakvih zadataka superioran učinak ostvarili upravo pojedinci sa elementima razvijene autonomne ekstrinzičke motivacije. Puno razumevanje okolnosti u kojima bi se formirala i održavala autonomna ekstrinzička motivacija imalo bi veliku praktičnu vrednost za organizacije. Ponajviše za strukturisanje motivacije zaposlenih kada organizacije diktiraju radne zadatke u kojima je neophodna izrazita upornost, disciplina i velika angažovanost za njihovo izvršavanje. A to se najčešće i dešava u realnom radu.

Koje su to okolnosti koje bi mogle pogodovati formiranju i održavanju AEM? Teorija self-determinacije za sada pretpostavlja da bi iste one okolnosti koje omogućavaju razvojno formiranje intrinzičke motivacije dovele i do internalizacije i integracije ekstrinzičkih regulativa kod odraslih osoba, odnosno, do formiranja AEM. Te okolnosti se odnose na socijalni kontekst u kome osoba percipira mogućnost izbora, dobija objašnjenja dubljeg smisla određene aktivnosti kao i uvažavanje njenih stavova i osećanja prema datoj aktivnosti (npr. od strane neposrednog rukovodioca). Teorija takođe pretpostavlja i da osobe koje već poseduju autonomnu kauzalnu orijentaciju budu i prijemčivije za takve okolnosti i za formiranje AEM. Donji model (Slika 3) subsumira ove faktore kao i očekivane konsekvence AEM-a. Dalja istraživanja su potrebna da bi se ovaj hipotetski model empirijski validirao. 


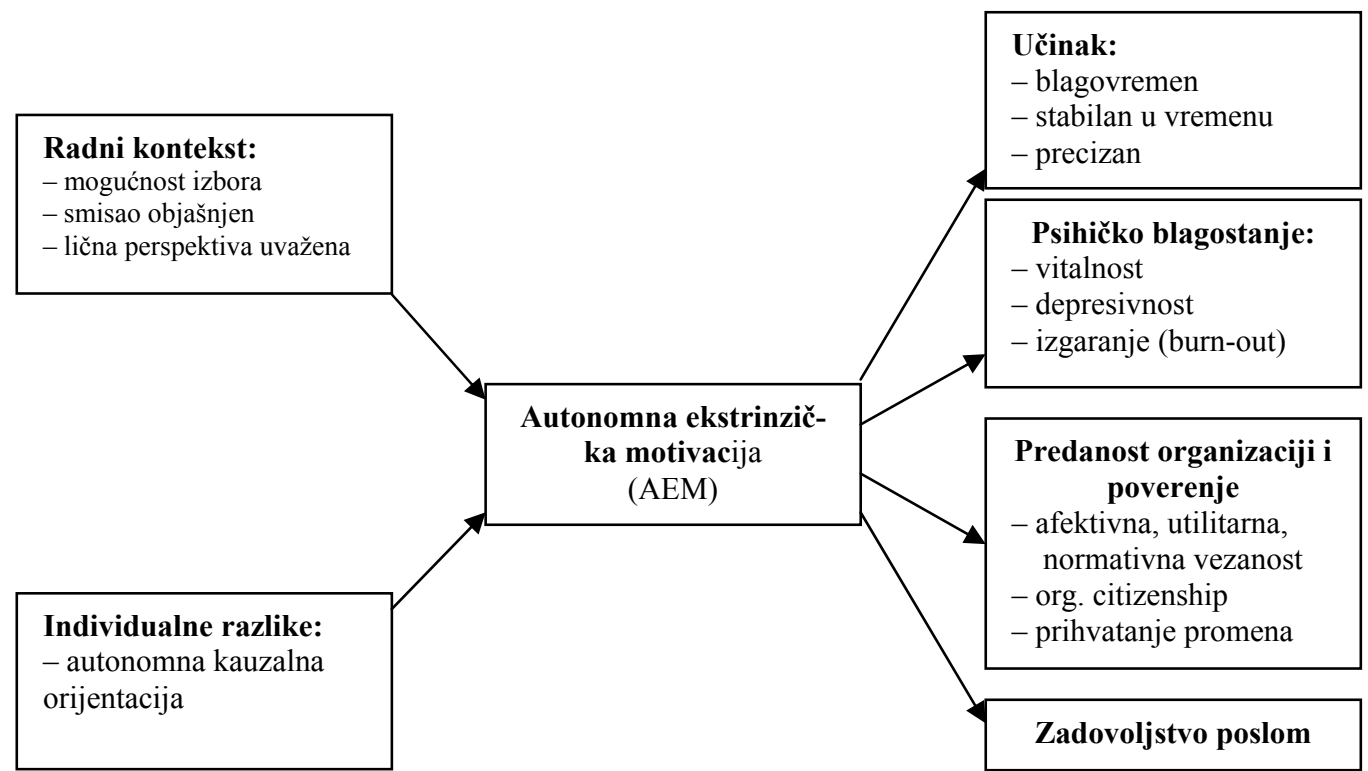

Slika 3. Hipotetski model autonomne ekstrinzičke motivacije (AEM)

\section{Zaključak}

Cilj ovog teksta bio je da se ukratko prikažu iskustva u primeni teorije selfdeterminacije na problem radne motivacije, da se ova teorija odredi prema drugim teorijama u polju, kao i da se predloži program za buduća istraživanja. Istaknuto je da teorija self-determinacije vidi dva oblika regulacije organizacijskog ponašanja (autonomni i kontrolišući) kao rezultantu uticaja socijalnog okruženja (složenosti rada, radnog konteksta i klime) i individualnih razlika u kauzalnim orijentacijama. Takođe je definisan odnos između teorije self-determinacije i procesnih teorija kao i teorije postavljanja ciljeva i humanističkih teorija motivacije za rad. Konačno, naglašena je potreba daljih istraživanja koncepta autonomne ekstrinzičke motivacije kao i vrednost ovog koncepta za izgradnju radne motivacije u uobičajenim organizacijskim uslovima. Istaknuto je da teorija selfdeterminacije predstavlja sadržajnu teoriju motivacije koja je razvila humanistički koncept potreba rasta i primenila ga u tumačenju nastanka i održanja autonomne regulacije radnog ponašanja. Principi ove teorije, za razliku od principa drugih teorija u humanističkom korpusu, su primili impozantnu empirijsku podr- 
šku, pre svega kada su primenjeni u analizi uticaja sredinskih faktora u nastanku autonomne i kontrolisane regulacije kao i u analizi njihovih posledica na ponašanje i blagostanje pojedinca. Ipak, u poređenju sa drugim domenima testiranja, ova teorija je daleko manje korištena u organizacijskim studijama. S obzirom na potvrđen potencijal kojim ova teorija raspolaže, može se preporučiti istraživačima organizacijskog ponašanja da ozbiljno razmotre korišćenje konceptualnih i tehničkih resursa teorije self-determinacije u svojim studijama.

\section{Reference}

Alderfer, C. P. (1972). Existence, relatedness, and growth. New York: Free Press.

Baard, P.P., Deci, E. L. \& Ryan, R. M. (2004). Intrinsic Need Satisfaction: A Motivational Basis of Motivation and Well-Being in Two Work Settings. Journal of Applied Social Psychology. 34, 10, 2045-2068.

Deci, E. L. \& Ryan, R. M. (1980). The empirical exploration of intrinsic motivational processes. In L Berkowitz (Ed.), Advances in experimental social psychology (Vol. 13, pp. 39-80). New York: Academic.

Deci, E. L. \& Ryan, R. M. (1985a). Intrinsic motivation and self-determination in human behaviour. New York: Plenum Press.

Deci, E. L., Ryan, R. M., Gagne', M., Leone, D. R., Usunov, J., \& Kornazheva, B. P. (2001). Need satisfaction, motivation, and well-being in the work organizations of a former Eastern Bloc country. Personality and Social Psychology Bulletin, 27, 930-942.

Deci, E. L. \& Ryan, R. M. (2002). Handbook of Self-Determination Research. Rochester: The University of Rochester Press.

Deci, E. L. (1971). Effects of externally mediated rewards on intrinsic motivation. Journal of Personality and Social Psychology, 18, 105-115.

Deci, E. L. (1975). Intrinsic motivation. New York: Plenum.

Deci, E. L., \& Ryan, R. M. (1985b). The general causality orientations scale: self-determination in personality. Journal of Research in Personality, 19, 109-134.

Deci, E. L., Connell, J. P., \& Ryan, R. M. (1989). Self-determination in a work organization. Journal of Applied Psychology, 74, 580-590.

Deckop, J. R., \& Cirka, C. C. (2000). The risk and reward of a double-edged sword: effects of merit-pay programs on intrinsic motivation. Nonprofit and Voluntary Sector Quarterly, 29, 400-418. 
Eden, D. (1975). Intrinsic and extrinsic rewards and motives: replication and extension with Kibbutz workers. Journal of Applied Social Psychology, 5, $348-361$.

Gagne', M., \& Koestner, R. (2002). Self-determination theory as a framework for understanding organizational commitment. Paper presented at the annual meeting of the Society for Industrial and Organizational Psychology, Toronto, Canada.

Gagne', M., Boies, K., Koestner, R., \& Martens, M. (2004). How work motivation is related to organizational commitment: a series of organizational studies. Manuscript, Concordia University.

Grolnick, W. S., \& Ryan, R. M. (1987). Autonomy in children's learning: an experimental and individual difference investigation. Journal of Personality and Social Psychology, 52, 890-898.

Herzberg, F. (1966) Work and the nature of man. Cleveland, OH: World.

Koestner, R., \& Losier, G. F. (2002). Distinguishing three ways of being internally motivated: a closer look at introjection, identification, and intrinsic motivation. In E. L. Deci, \& R. M. Ryan (Eds.), Handbook of selfdetermination research (pp. 101-121). Rochester, NY: University of Rochester Press.

Lam, C.F. \& Gurland, T.G. (2008). Self-determined work motivation predicts job outcomes, but what predicts self-determined work motivation? Journal of Research in Personality 42, 1109-1115.

Locke, E. A., \& Latham, G. P. (1990). A theory of goal setting and task performance. Englewood Cliffs, NJ: Prentice-Hall.

Majstorović, N. (2007). The Mediating Role of Self Orientations on the Relationship between Psychological Needs Satisfaction and Values. PhD thesis, University of Ottawa, Ottawa, Canada.

Majstorović, N. (2008). Relacije između prevalentnog tipa self-regulacije i sistema univerzalnih ljudskih vrednosti. Neobjavljen rad.

Maslow, A. H. (1954). Motivation and personality. New York: Harper \& Row.

Matteson, M. T., \& Ivancevich, J. M. (1987). Controlling work stress: Effective human resource and management strategies. San Francisco, CA: JosseyBass Inc.

Porter, L. W., \& Lawler, E. E. III. (1968). Managerial attitudes and performance. Homewood, IL: Irwin-Dorsey. 
Sheldon, K. M., \& Elliot, A. J. (1998). Not all personal goals are 'personal': comparing autonomous and controlling goals on effort and attainment. Personality and Social Psychology Bulletin, 24, 546-557.

Vallerand, R. J., Pelletier, L.G. \& Koestner, R. (2008). Reflections on SelfDetermination Theory. Canadian Psychology, Vol. 49, No. 3, 257-262.

Vroom, V. H. (1964). Work and motivation. New York: Wiley 


\title{
ABSTRACT
}

\section{APPLICATION OF THE SELF-DETERMINATION THEORY IN WORK MOTIVATION RESEARCH}

\author{
Nebojša Majstorović
}

The Self-Determination Theory develops an integrative approach to the delicate scientific phenomenon of motivation by linking inherited growth needs to active human nature which, in its own normality and favorable environmental conditions, tends to develop an autonomous behavioural regulation and to integrate one's life experience and personal dispositions into a coherent system of self. This theory considers cases of overarching external pressure that leads toward the frustration of growth needs as well as to the development of controlling motivational regulation or a state of amotivation. The assumptions of SDT have been tested in numerous domains such as learning, work, sport, intimate relationships, pro-social behaviour and many others. The main goal of this text is to present existing experience in the application of SDT within the analysis of organizational behaviour, to position this theory regarding other theories of work motivation, as well as to indicate potential directions for future studies that would come out from its conceptual framework.

Key words: self-determination, work motivation, self, behavioural regulation 